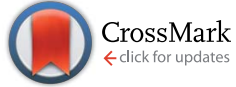

Cite this: RSC Adv., 2015, 5, 10974

Received 30th September 2014 Accepted 5th January 2015

DOI: $10.1039 / c 4 r a 11537 f$

www.rsc.org/advances

\title{
Effect of incorporation of POSS compounds and phosphorous hardeners on thermal and fire resistance of nanofilled aeronautic resins $\uparrow$
}

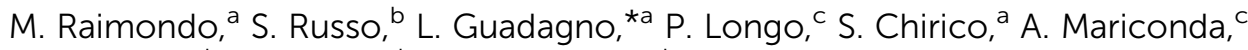 \\ L. Bonnaud, ${ }^{d}$ O. Murariu' ${ }^{d}$ and Ph. Dubois ${ }^{d}$
}

The aim of this work is the identification of the best strategy for improving thermal, fire resistance and electrical conductivity of an epoxy resin for aeronautic applications. The effect of DodecaPhenyl POSS (DPHPOSS), Epoxycyclohexyl POSS (ECPOSS), Glycidyl POSS (GPOSS) and TriglycidylCyclohexyl POSS (TCPOSS) to act as flame retardants of the resin was evaluated. Flame retardancy tested by the limiting oxygen index (LOI) indicated that GPOSS has meaningful effects on the flame retardancy of the epoxy mixture. The incorporation of $5 \mathrm{wt} \%$ of GPOSS into the epoxy matrix resulted in a LOI value of 33 with respect to 27 of the pure epoxy mixture. The trend observed by LOI tests was confirmed by mass loss calorimetry measurements: a decrease from $540 \mathrm{~kW} \mathrm{~m}^{-2}$ down to $327 \mathrm{~kW} \mathrm{~m}^{-2}$ was observed in the peak of heat release rate (PHRR). LOI and PHRR values were compared with those obtained for the same resin replacing the 4,4'-diaminodiphenyl sulfone (DDS) with the bis(3-aminophenyl) phenylphosphineoxide (BAPPO) and the bis(3-aminophenyl) methyl phosphine oxide (BAMPO). BAMPO and BAPPO proved to be more effective than POSS compounds to increase LOI values. Carbon nanotubes (CNTs), embedded inside the epoxy resin to enhance electrical conductivity, are found to affect significantly fire properties of epoxy systems mainly by preventing the epoxy systems from forming intumescent charring.

\section{Introduction}

Thermosetting structural materials can be designed to be applied as multifunctional resins. Materials of this kind have tremendous potential to impact future structural performance by reducing size, weight, cost, power consumption and complexity while improving efficiency, safety and versatility. Successful strategies to reduce the flammability of epoxy resins, simultaneously increasing the electrical conductivity, are extremely important in the field of aeronautic and aerospace applications. Currently, in the field of conductive lightweight resins, the material scientists have the possibility "to use" the advantages of the nanotechnologies in addition to the classical methods to protect the materials. In particular, many

${ }^{a}$ Dipartimento di Ingegneria Industriale, Università di Salerno, Via Giovanni, Paolo II, 132, 84084 Fisciano (SA), Italy. E-mail: lguadagno@unisa.it; Fax: +39089964057

${ }^{b}$ ALENIA Aeronautica SpA Viale dell'Aeronautica, 80038 Pomigliano D'Arco - (NA), Italy

'Dipartimento di Chimica e Biologia, Università di Salerno, Via Giovanni, Paolo II, 132, 84084 Fisciano (SA), Italy

${ }^{d}$ Laboratory of Polymeric and Composite Materials, Center of Innovation and Research in Materials \& Polymers (CIRMAP), Materia Nova Research Center \& University of Mons, 20 Place du Parc, 7000 - Mons, Belgium

$\dagger$ Electronic supplementary information (ESI) available. See DOI: $10.1039 / \mathrm{c} 4 \mathrm{ra} 11537 \mathrm{f}$ researchers are focusing on developing conductive nanostructured carbon forms to be embedded in the epoxy resins for improving electrical conductivity of the composite.

Moreover, flame resistance of nanofilled epoxy resins can be improved by using Polyhedral Oligomeric Silsesquioxanes (POSS) compounds or new phosphorous hardeners. In a recent paper, the authors investigate the effects of the incorporation of OctaMethylOligomericSilsesquioxanes (OMPOSS) and carbon nanotubes (CNTs) on the reaction to fire of an epoxy resin containing ammonium polyphosphate (APP) (a conventional intumescent flame retardant) cured with diethylenetriamine (DETA). ${ }^{1}$ They found that the combination of APP and CNTs provides no enhancement of the reaction to fire of this system; whereas using OMPOSS in combination with APP, a large synergistic effect via an intumescence phenomenon is observed. Other authors have formulated epoxy composite with $2 \mathrm{wt} \%$ of octa-aminophenyl polyhedral oligomericsilsequioxanes-reduced graphene oxide (OapPOSS-rGO) by using as cross-linking agent $4,4^{\prime}$-diamino diphenylmethane (DDM). ${ }^{2}$ They found that with the incorporation of $2 \mathrm{wt} \%$ of OapPOSS-rGO, the onset thermal degradation temperature of epoxy composite was increased by $43{ }^{\circ} \mathrm{C}$. In addition, the peak heat release rate, total heat release and CO production rate were reduced by $49 \%, 37 \%$ and $58 \%$, respectively, compared to those of neat epoxy. The positive influence of POSS materials to act as fire retardants was found 
also for thermoplastic polymer for example for polyether-blockpolyamide system (50-70\% reduction of the PHRR), for polypropylene ( $40 \%$ reduction of PHRR) and a styrene-butadienestyrene (SBS) triblock polymer (40-60\% reduction of PHRR). ${ }^{3}$ Other successful strategies for improving flame resistance are based on the use of phosphorous compounds. They could impart flame retardancy through flame inhibition in the gas phase and char enhancement in the condensed phase. ${ }^{4-10}$ Considering these promising results, we have undertaken a study aimed at understanding the effect of different nanostructured carbon forms on the fire behaviour of aeronautic resins containing functionalized and unfunctionalized POSS compounds.

Several studies have been reported in the literature concerning curing of epoxy resins with phosphorous flame retardants, as well as the thermal and combustion performance of the resins containing these compounds. ${ }^{11-16}$ Varma and Gupta ${ }^{17}$ found that glass fabric reinforced laminates based on DGEBA and BAMPO exhibited a higher limiting oxygen index, than those based on the DGEBA/DDS system. Epoxy resins cured with BAMPO exhibited higher char yields when compared to those cured by DDS.

Levchik et al. ${ }^{12,18}$ showed that the fire retardant effectiveness of the BAMPO goes through a maximum with increasing phosphorus concentration in a tetraglycidylmethylenediphenylamine/ DGEBA epoxy blend. This was attributed to the competition between the char forming fire retardant action and promotion of the evolution of combustible gases because of the catalysis of degradation. Interestingly, not many studies can be found concerning the ability of carbon nanotubes (CNT) to improve flame retardancy and thermal stability of epoxy resins and they present contradictory conclusions. Indeed, Tao et al. ${ }^{19}$ report that CNT negatively affect the thermal stability of epoxy matrices. More specifically, they found the incorporation of CNT in epoxy accelerates the thermal degradation of epoxy and lowers its degradation temperature. The authors explain the lowered degradation temperature by an effect of the CNT on the extent of curing of the epoxy matrix yielding an epoxy/CNT nanocomposite containing unreacted components that decompose at lower temperatures. In addition, the presence of metallic catalyst residues in the CNT might also catalyze the decomposition of the epoxy. Other studies by Jyotishkumar et al. ${ }^{20}$ confirm the decrease in overall curing density of epoxy matrices by the addition of CNT. Contrary to Tao and coll., Katsoulis et al. ${ }^{21}$ observe no significant alteration of the thermal stability of the epoxy system in presence of double-wall carbon nanotubes, but they do not notice a significant effect on the fire reaction properties of the epoxy composite whereas Lee et al..$^{22}$ obtain an improvement of the flame retardant and anti-oxidation properties of epoxy systems with addition of CNT or layered clay. Rahatekar et al. ${ }^{23}$ studied the effect of CNT or layered clay (MMT type) on the flammability of epoxy systems. They found that integrity of the residue/char formed from epoxy/CNT composites was superior to that of epoxy/MMT composites. They also observed a significant increase in thermal conductivity of epoxy/CNT composites with high loading of CNT. The enhanced thermal conductivity of epoxy/CNT composites was found to be responsible for the initial mass loss reduction.
Braun et al. highlighted that epoxy resins based composites containing phosphine oxide shows good performance in terms of flammability and fire behavior. ${ }^{24}$

In this paper we propose formulations of multifunctional epoxy resins characterized by improved flame resistance incorporating electro-conductive nanofillers. DC conductivity $\left(\mathrm{S} \mathrm{m}^{-1}\right)$ values of the formulated resins range between $3.5 \times 10^{-3}$ and $1.68 \times 10^{-1} \mathrm{~S} \mathrm{~m}^{-1}$. LOI $\left(\% \mathrm{O}_{2}\right)$ values range between 30.2 and 40 and PHRR $\left(\mathrm{kW} \mathrm{m}^{-2}\right)$ range between 293 and 629. The nanofilled samples behave as multifunctional systems to increase flame resistance and electrical conductivity.

\section{Experimental}

\subsection{Materials}

The epoxy matrix T20B was prepared by mixing an epoxy precursor, tetraglycidyl methylene dianiline (TGMDA) (epoxy equivalent weight $117-133 \mathrm{~g} \mathrm{eq}^{-1}$ ), with an epoxy reactive monomer 1-4 butanediol diglycidyl ether (BDE) at a concentration of $80 \%: 20 \%$ (by wt) respectively.

Four different POSS compounds were dispersed in the epoxy matrix: GPOSS, TCPOSS and ECPOSS functionalized with a different number of oxirane rings, and DPHPOSS functionalized with phenyl groups. The structures of the used organic substituted POSS compounds are shown in Table 1. POSS/epoxy composites were prepared with $5 \mathrm{wt} \%$ of POSS.

The curing agent used for the curing was $4,4^{\prime}$-diaminodiphenyl sulfone (DDS). This hardener agent was added at a stoichiometric concentration with respect to all the epoxy rings (TGMDA, BDE and POSS - in the case of POSS with epoxy rings).

Flame retardation of the epoxy resin containing the reactive diluent was also evatuated for the formulation solidified with BAMPO and BAPPO.

BAMPO and BAPPO were synthesized, the synthesis procedure of these two hardeners is shown in the section "ESI $\dagger$ ", while TGMDA, BDE, DDS were obtained from Sigma-Aldrich, and POSS compounds from Hybrid Plastics Company.

\subsection{Characterizations and Experimental procedure}

Epoxy blends and DDS were mixed at $120^{\circ} \mathrm{C}$ and all the samples were cured by a two-stage curing cycles: a first isothermal stage was carried out at the lower temperature of $125{ }^{\circ} \mathrm{C}$ for 1 hour and the second isothermal stage at higher temperatures up to $200{ }^{\circ} \mathrm{C}$ for 3 hours.

Fire resistance of POSS based epoxy samples was characterized by limiting oxygen index measurement (LOI) and mass loss calorimetry.

Experimental conditions for LOI tests: barrels of $80 \times 10 \times$ $3 \mathrm{~mm}^{3}$ are fixed in a vertical position and their top is inflamed with a burner. LOI, the minimum concentration of oxygen in a nitrogen/oxygen mixture required to just support the sample combustion, was measured following standard ASTM 2863. 
Table 1 POSS compounds investigated in this paper

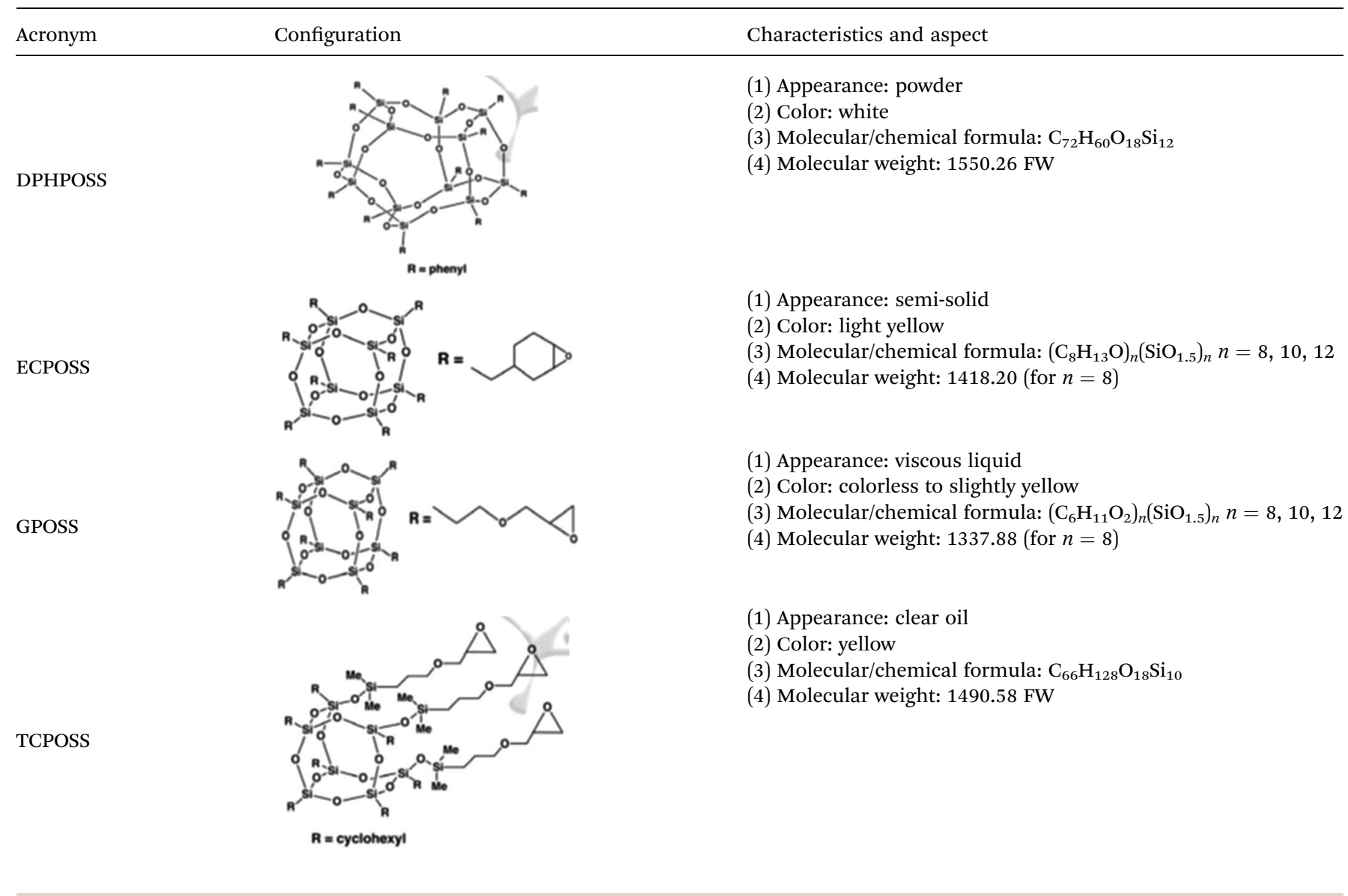

Experimental conditions for Mass loss calorimeter: plates of $100 \times 100 \times 3 \mathrm{~mm}^{3}$ are exposed to a radiant cone $\left(50 \mathrm{~kW} \mathrm{~m}{ }^{-2}\right)$ using a forced ignition. The heat of combustion released was measured using a thermopile according to standard ISO 13927.

Thermogravimetric analysis (TGA) was carried out using a Mettler TGA/SDTA 851 thermobalance. Resin samples were heated from $25^{\circ} \mathrm{C}$ to $900{ }^{\circ} \mathrm{C}$ at a $10^{\circ} \mathrm{C} \mathrm{min}^{-1}$ heating rate under air and nitrogen flow. The weight loss was recorded as a function of the temperature.

The dispersion behavior of two different reactive organophosphorus compounds bis(3-aminophenyl) methyl phosphine oxide (BAMPO) and bis(3-aminophenyl) phenyl phosphine oxide (BAPPO) in the thermosetting mixture (T20BD) has been investigated. These two compounds act as curing agents becoming an integral part of the thermosetting matrix (with the same initial reactions as those activated by $4,4^{\prime}$-diaminodiphenyl sulfone (DDS) hardener agent used for the formulation containing the selected POSS). BAMPO and BAPPO were added at a stoichiometric concentration with respect to all the epoxy rings (TGMDA and BDE).

The dispersion methods were evaluated with the aim of choosing the best procedure to obtain the optimal dispersion of these compounds inside the epoxy formulation.

Epoxy blends and BAMPO were mixed by magnetic stirring at $70{ }^{\circ} \mathrm{C}$. The degassing of the mixture was performed at $45^{\circ} \mathrm{C}$.
Epoxy blends and BAPPO were mixed by magnetic stirring at $95{ }^{\circ} \mathrm{C}$. The degassing of the mixture was performed at $55{ }^{\circ} \mathrm{C}$.

The MWCNTs (3100 Grade) were obtained from Nanocyl S.A. Transmission electron microscopy (TEM) investigation has shown for MWCNTs an outer diameter ranging from 10 to $30 \mathrm{~nm}$. The length of MWCNTs is from hundreds of nanometers to some micrometer. The number of walls varies from 4 to 20 in most nanotubes. The specific surface area of MWCNTs determined with the BET method is around $250-300 \mathrm{~m}^{2} \mathrm{~g}^{-1}$; the carbon purity is $>95 \%$ with a metal oxide impurity of $5 \%$ as it results by thermogravimetric analysis.

\section{Results and discussion}

\subsection{Evaluation of the POSS compounds as compounds for improving fire properties}

3.1.1 Sample preparation. POSS dispersion methods were evaluated with the aim of choosing the best procedure to obtain the optimal dispersion of these compounds inside the epoxy formulation.

An efficient method to obtain a good dispersion was developed consisting in one or two steps; in the first step POSS compounds were ultrasonicated inside the liquid epoxy formulation at $90{ }^{\circ} \mathrm{C}$, in the second step, the dispersion was optimized by magnetic stirring at $120^{\circ} \mathrm{C}$. 
Optical stereo-microscope analysis was performed in order to evaluate the dispersion level of the POSS in the epoxy mixture.

Results on the dispersion of DPHPOSS in the epoxy mixture. DPHPOSS powder was dispersed at a percentage of $5 \mathrm{wt} \%$ in the epoxy mixture T20BD obtaining the sample T20BD $+5 \%$ DPHPOSS; before to apply the mechanical agitation via ultrasonic waves, a preliminary analysis of the sample T20BD $+5 \%$ DPHPOSS was performed by optical microscopy (see Fig. 1).

As expected, several aggregates of DPHPOSS molecules are detectable, indicating that POSS's cage crystalline aggregates were almost intact. A relevant average size reduction of dispersed POSS phase was achieved by ultrasonication for 20 minutes (see Fig. 2).

The followed magnetic stirring step performed at $400 \mathrm{rpm}$ in oil bath at $120{ }^{\circ} \mathrm{C}$ for 1 hour, did not lead to any relevant differences in the POSS dispersion. The microscope images showed phenomena of re-aggregation (see Fig. 3). The results on the dispersion of DPHPOSS in the T20B mixture indicates that this POSS is not epoxy-soluble and only the first step must be applied to ensure a better dispersion of POSS powder in the epoxy matrix.

Results on the dispersion of ECPOSS in the epoxy mixture. ECPOSS was dispersed at a percentage of $5 \mathrm{wt} \%$ in the epoxy mixture T20BD obtaining the sample T20BD $+5 \%$ ECPOSS. Visual assessment of this sample, after ultrasonication followed by a treatment of $1 \mathrm{~h}$ in a stirred oil bath at $120{ }^{\circ} \mathrm{C}$, showed a clear mixture (see Fig. 4).

In support of these results, optical stereo-microscope examination of sample was performed by using high resolution stereo inspection. It was found that few small aggregates (not visible to the naked eye) were present after the ultrasonication,
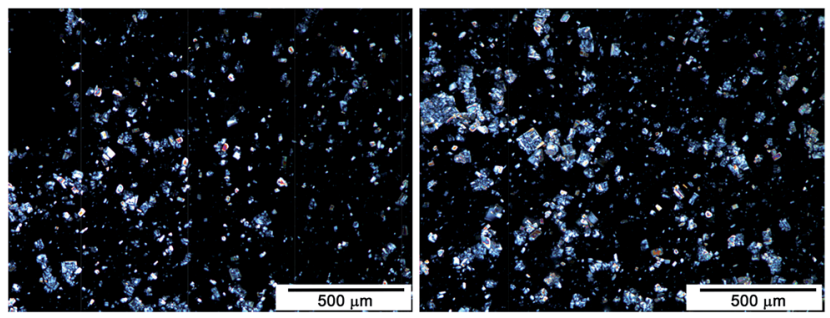

Fig. 1 Optical image of TB2OD + 5\% DPHPOSS sample (before ultrasonication).
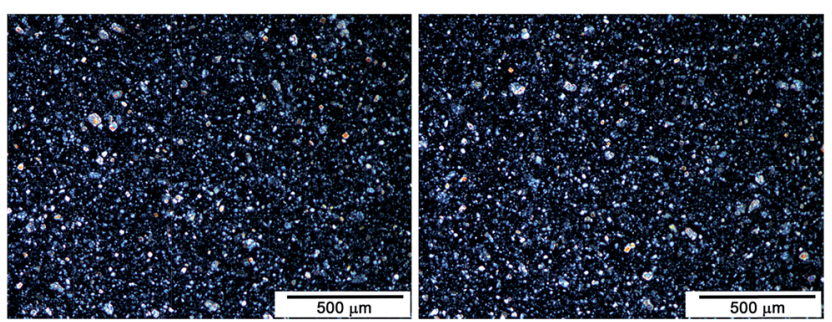

Fig. 2 Optical image of T20BD $+5 \%$ DPHPOSS sample (after ultrasonication).
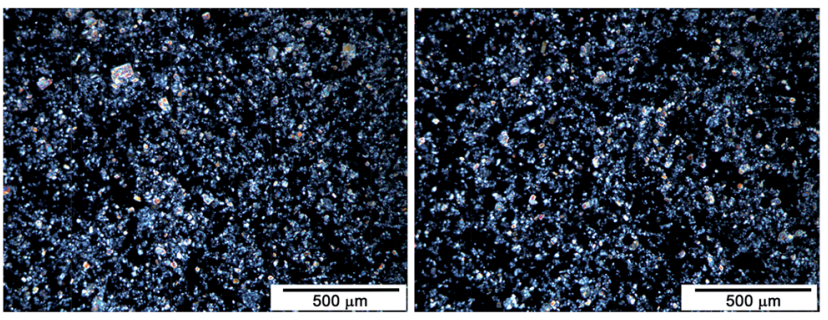

Fig. 3 Optical image of T20BD + 5\% DPHPOSS sample (after ultrasonication and magnetic stirring in oil bath at $120{ }^{\circ} \mathrm{C}$ for $1 \mathrm{~h}$ ).

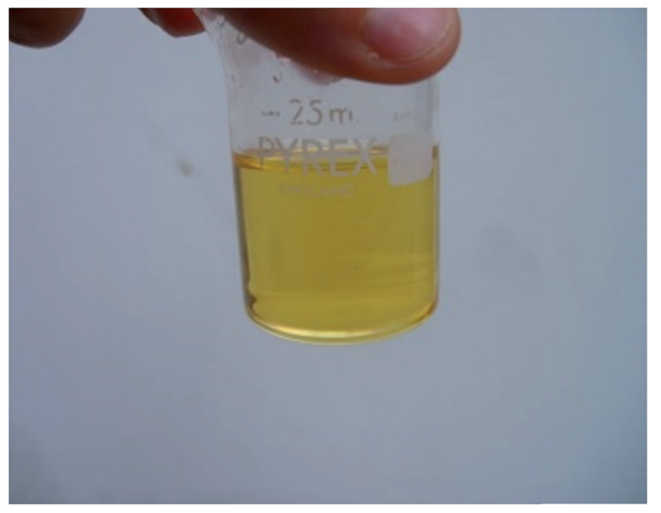

Fig. 4 Photo of T20BD + 5\% ECPOSS mixture after ultrasonication and1 $\mathrm{h}$ in a stirred oil bath at $120^{\circ} \mathrm{C}$.

the heating stirring action at $120{ }^{\circ} \mathrm{C}$ further reduces the dimension of these aggregates improving the dispersion; consequently the final material appears as a random few POSS aggregates in the liquid epoxy mixture (see Fig. 5).

Results on the dispersion of GPOSS in the epoxy mixture. GPOSS in the form of viscous liquid was dispersed at a percentage of $5 \mathrm{wt} \%$ in the epoxy mixture T20BD obtaining the sample $\mathrm{T} 20 \mathrm{BD}+5 \%$ GPOSS.

Visual assessment of sample after ultrasonication highlighted the presence of filamentous residues (see Fig. 6 - on the left). The subsequent stirring step in heated oil bath causes the dissolution of the filamentous residues, consequently the sample becomes clear (see Fig. 6 - on the right).

As for the previous sample, optical stereo-microscope examinations of sample by using high resolution stereo inspection have shown a very good level of GPOSS solubility inside the matrix after the second step (see Fig. 7).

Results on the dispersion of TCPOSS in the epoxy mixture. TCPOSS liquid was dispersed at a percentage of $5 \mathrm{wt} \%$ in the epoxy mixture T20BD obtaining the sample T20BD $+5 \%$ TCPOSS.

Visual assessment of T20BD $+5 \%$ TCPOSS sample shows particle suspensions in the sample detectable also after sonication. Nevertheless, the subsequent stirring step in the heated oil bath causes dissolution of this residue making clear the sample with no particles visible to the naked eye. Optical stereomicroscope examinations of sample by using high resolution stereo inspection have shown very small aggregates well 

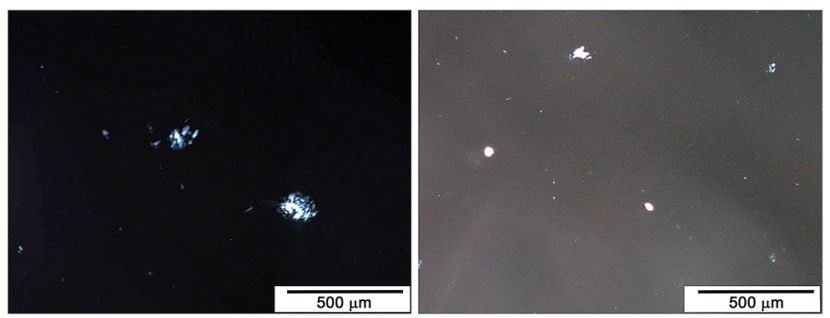

Fig. 5 Optical image of T20BD + 5\% ECPOSS sample after ultrasonication (on the left) and magnetic stirring in oil bath at $120^{\circ} \mathrm{C}$ for $1 \mathrm{~h}$ (on the right).

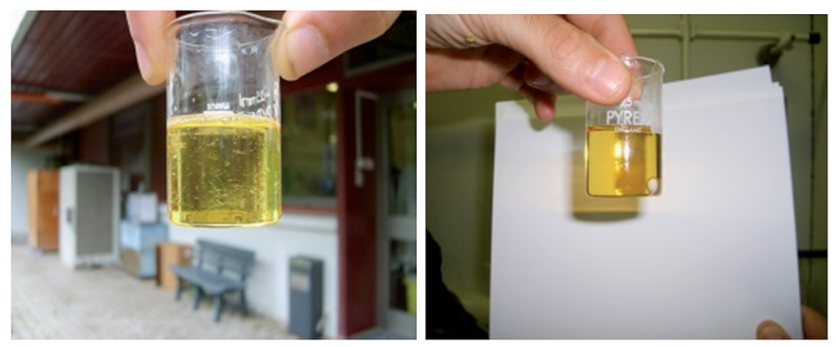

Fig. 6 Photos of T2OBD + 5\% GPOSS mixture after ultrasonication (on the left) and after $1 \mathrm{~h}$ in a stirred oil bath at $120^{\circ} \mathrm{C}$ (on the right).

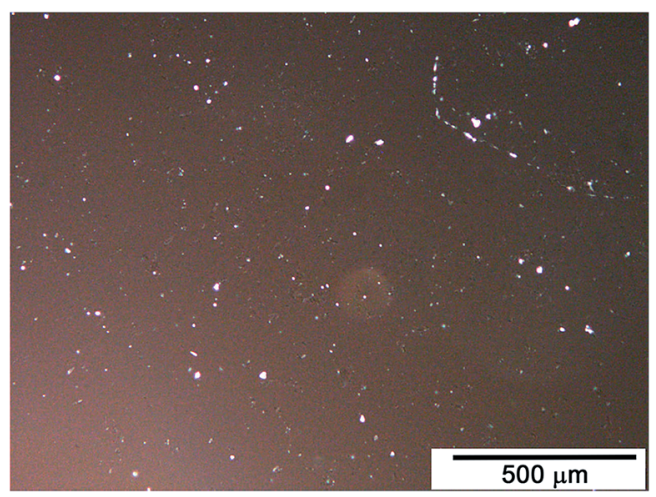

Fig. 7 Optical image of T20BD $+5 \%$ GPOSS sample after ultrasonication and magnetic stirring in oil bath at $120^{\circ} \mathrm{C}$ for $1 \mathrm{~h}$.

distributed into the epoxy formulations after the two steps of ultrasonication and magnetic stirring in oil bath at $120{ }^{\circ} \mathrm{C}$ for $1 \mathrm{~h}$ (see Fig. 8).

In conclusion, data on the dispersion of the analyzed POSS inside the epoxy mixture T20B show that the structure of POSS plays an important role on the dissolution/dispersion of these compound into the matrix. In particular, GPOSS that is fully epoxidized with glycidyl groups is compatible with epoxy precursors and shows good level of dissolution into the initial liquid epoxy mixture after the two steps of ultrasonication and magnetic stirring at $120{ }^{\circ} \mathrm{C}$. DPHPOSS which contains no epoxy group does not dissolve into the epoxy formulations. However, the only ultrasonication step allows to obtain an homogeneous dispersions of very small aggregates inside the formulation.

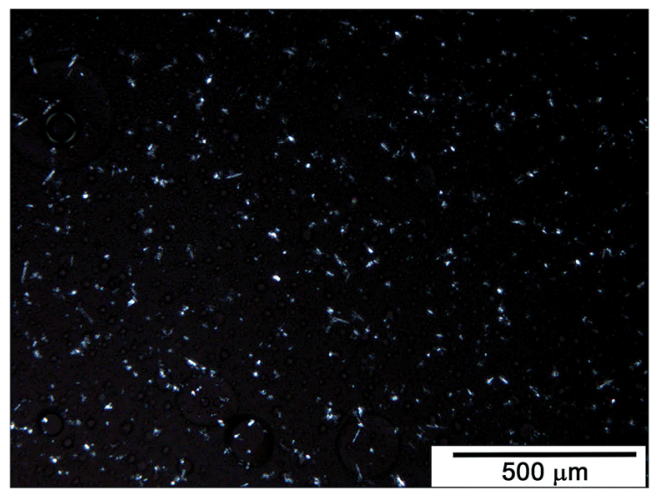

Fig. 8 Optical image of T2OBD $+5 \%$ TCPOSS sample after ultrasonication and magnetic stirring in oil bath at $120{ }^{\circ} \mathrm{C}$ for $1 \mathrm{~h}$.

3.1.2 Thermogravimetric analysis. Thermogravimetric curves in air for POSS, epoxy mixture T20BD and epoxy mixture $+5 \%$ POSS (T20BD $+5 \%$ POSS) as a function of temperature are shown in Fig. 9a.

The thermal degradation process of pure POSS compounds is different for the four samples. The initial decomposition temperature that was defined as $5 \%$ mass loss temperature is $285{ }^{\circ} \mathrm{C}$ for TCPOSS, $320{ }^{\circ} \mathrm{C}$ for GPOSS, $405^{\circ} \mathrm{C}$ for ECPOSS and $500{ }^{\circ} \mathrm{C}$ for DPHPOSS which appears to be more thermostable than other POSS. The inorganic Yields at $900{ }^{\circ} \mathrm{C}$ are $c a .35,38$, 43 and $47 \mathrm{wt} \%$ for ECPOSS, GPOSS, TCPOSS and DPHPOSS respectively which are very close to the theoretical inorganic yield (residual silica). The considerable differences detected in the initial decomposition temperature of the pure POSS compounds are not reflected in the epoxy formulations containing the different POSS (for the chosen compositions). In fact, for the pure epoxy formulation, the initial decomposition occurs at $340{ }^{\circ} \mathrm{C}$. This value is the same detected for the formulation containing GPOSS, whereas the initial decomposition temperature of the formulations containing TCPOSS, ECPOSS and DPHPOSS is $370{ }^{\circ} \mathrm{C}$.

As expected, no residual yield was obtained at $900{ }^{\circ} \mathrm{C}$ for the pure epoxy formulation. In terms of the initial decomposition temperatures, the thermal stability of hybrids based on TCPOSS, ECPOSS and DPHPOSS was found to be enhanced of $30{ }^{\circ} \mathrm{C}\left(370{ }^{\circ} \mathrm{C}\right.$ with respect to the value of $\left.340{ }^{\circ} \mathrm{C}\right)$. Thermogravimetric analysis shows that all the T20BD $+5 \%$ POSS samples are thermostable up to $340{ }^{\circ} \mathrm{C}$.

Within the experimental temperature range, all the TG profiles display two-step degradation mechanism, suggesting that the inclusion of POSS in the matrix does not significantly modify the degradation mechanism of the formulation. The residual yields for the resin containing POSS compounds are between 2 and $5 \mathrm{wt} \%$, values very close to the theoretical values of the residual silica contents in the resin.

Fig. $9 \mathrm{~b}$ shows the thermal degradation process of the same components of Fig. 9a under nitrogen.

The initial decomposition temperatures of the pure POSS are $360{ }^{\circ} \mathrm{C}$ for TCPOSS, $340{ }^{\circ} \mathrm{C}$ for GPOSS, $420{ }^{\circ} \mathrm{C}$ for ECPOSS and $460^{\circ} \mathrm{C}$ for DPHPOSS. These values, with exception of DPHPOSS, are higher than those detected in air for all the analysed POSS. 
(a)

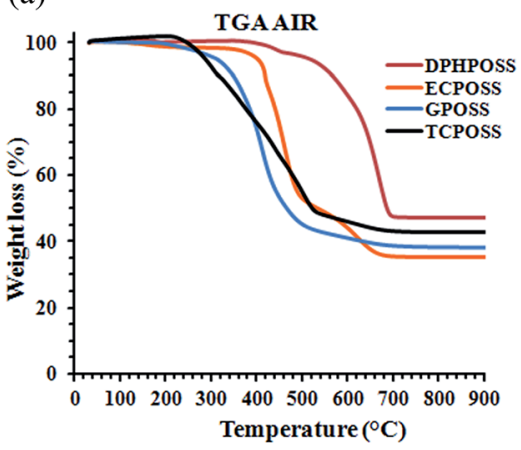

(b)

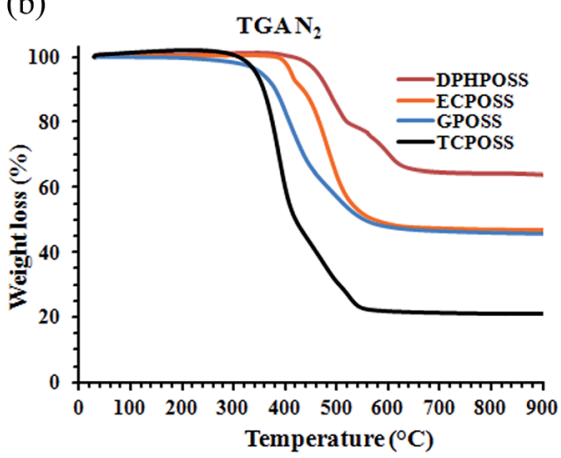

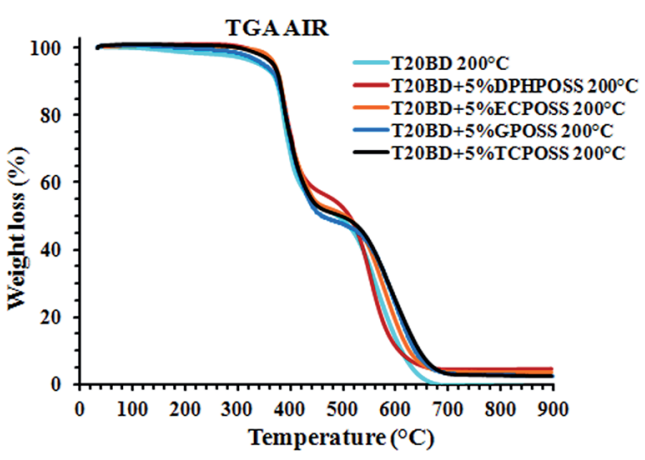

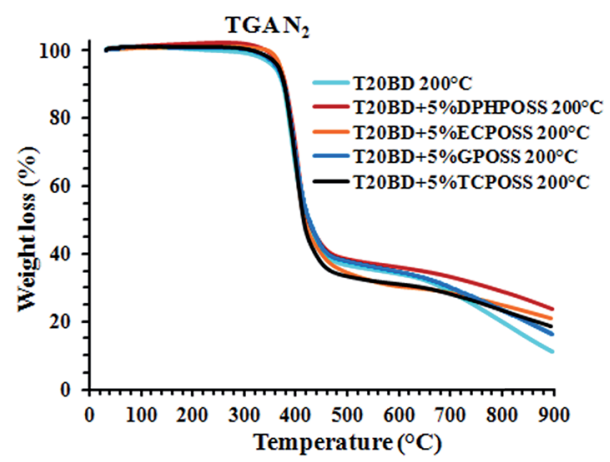

Fig. 9 (a) TG profiles of POSS (on the left side), T2OBD and T2OBD + 5\% POSS (on the right side) in air. (b) TG profiles of POSS (on the left side), $\mathrm{T} 20 \mathrm{BD}$ and $\mathrm{T} 20 \mathrm{BD}+5 \%$ POSS (on the right side) under nitrogen.

Under nitrogen atmosphere, the weight loss (\%) at $900{ }^{\circ} \mathrm{C}$ is $36 \%$ for DPHPOSS, $53 \%$ for GPOSS and ECPOSS and $80 \%$ for TCPOSS. In air (see Fig. 9a) the weight loss (\%) at the same temperature is 53\% for DPHPOSS, $63 \%$ for GPOSS, $65 \%$ for ECPOSS and $57 \%$ for TCPOSS. As expected, under nitrogen, for all the analysed POSS, the weight loss (\%) at $900{ }^{\circ} \mathrm{C}$ is lower than the values detected in air, with exception of TCPOSS. Under nitrogen, for TCPOSS, the residual weight is $c a$. $20 \%$ which is a value very close to the theoretical value of 18.84 corresponding to the inorganic yield composed of silicon. All the T20BD $+5 \%$ POSS samples in nitrogen atmosphere are thermostable up to $360{ }^{\circ} \mathrm{C}$. Similar to the behaviour in air, two distinct and wellseparated turns are observable in the TG curves in nitrogen; the first step is approximately in the same temperature range, whereas the second step is much slower with respect to the degradation in air. The first stage of thermal degradation for all the samples substantially occurs in the temperature range of $360-460{ }^{\circ} \mathrm{C}$, highlighting that there is no influence of POSS (for the chosen compositions) on the first step of the degradation process. A stabilizing effect of POSS seems to be active in the second stage of the degradation process at temperature higher than $700{ }^{\circ} \mathrm{C}$.

A significant difference in the mass loss after the first stage (thermal decomposition) is observable for experiments performed in air and nitrogen atmosphere. In fact, in nitrogen atmosphere it is between $62-66 \%$, while it is only $45-53 \%$ in air, this effect is also observed for the formulation T20BD without POSS compounds. This is a well-known behavior for thermosetting polymers where the oxygen is consumed primarily by gas-phase oxidation reactions during flaming burning of the nanocomposites, oxygen hardly reaches the thermally degrading sample surface beneath the evolved gaseous products. In fact, for these polymers the results of thermogravimetric tests performed in air would apply to smoldering combustion instead of flaming combustion. Therefore, it is recommended that TG tests for thermosetting polymer should also be performed in an inert atmosphere. ${ }^{25}$

3.1.3 Fire behavior of T20BD + 5\% POSS. The HRR versus time curves for the different samples are shown in Fig. 10.

Fire behavior of T20BD is clearly modified in presence of POSS. In addition to the significant decrease of the peak of heat release rate, the time of ignition is slightly increased for DPHPOSS, ECPOSS and GPOSS. Table 2 gathers the limiting oxygen index (LOI), the values of the peak of heat release rate (PHRR) and the total heat release (THR); errors based on the maximum deviation from single averaged values are provided. It appears that, the presence of POSS compounds undoubtedly acts as flame retardant for T20BD epoxy system as shown by the increase of LOI (with the exception of TCPOSS) and the decrease of the PHRR. GPOSS leads to the best increase of LOI $(22 \%$ with respect to T20BD value). The best behavior is also confirmed by the larger decrease in the PHRR; in fact, a decrease from $540 \mathrm{~kW} \mathrm{~m}^{-2}$ to $327 \mathrm{~kW} \mathrm{~m}^{-2}$ was observed in the PHRR of the T20BD $+5 \%$ GPOSS sample for which we can observe the smallest value for the samples without CNTs. These results are to be related to the fully epoxidized structure of GPOSS which allows a better dispersion of the POSS particles due to complete dissolution within T20BD (see Section 3.1.1 - Results on the dispersion of 


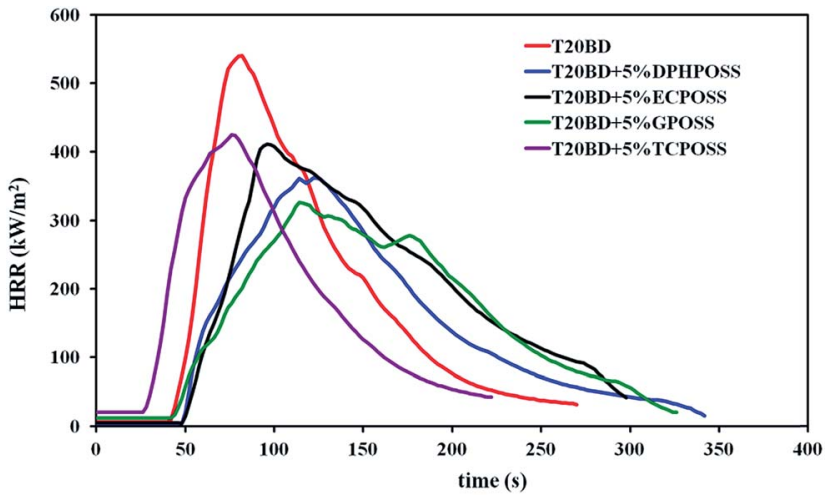

Fig. 10 HRR of T2OBD and T20BD + 5\% POSS formulations.

Table 2 LOI, PHRR and THR of the epoxy samples

\begin{tabular}{llll}
\hline Sample & $\begin{array}{l}\text { LOI }\left(\% \mathrm{O}_{2}\right) \\
(\% \pm 1)\end{array}$ & $\begin{array}{l}\text { PHRR } \\
\left(\mathrm{kW} \mathrm{m}^{-2}\right)\end{array}$ & $\begin{array}{l}\text { THR } \\
\left(\mathrm{MJ} \mathrm{m}^{-2}\right)\end{array}$ \\
\hline T20BD & 27 & $540 \pm 81$ & $48 \pm 8$ \\
T20BD + 5\% DPHPOSS & 30 & $362 \pm 54$ & $46 \pm 7$ \\
T20BD + 5\% ECPOSS & 28 & $411 \pm 62$ & $53 \pm 9$ \\
T20BD + 5\% GPOSS & 33 & $327 \pm 49$ & $49 \pm 8$ \\
T20BD + 5\% TCPOSS & 26 & $425 \pm 64$ & $40 \pm 6$ \\
T20BD + 5\% GPOSS + 0.5\% & 30 & $293 \pm 44$ & $47 \pm 10$ \\
CNT (3100) & & &
\end{tabular}

GPOSS in the epoxy mixture) and chemical linkages with the epoxy system. It is interesting to point out that DPHPOSS which exhibits the most thermostable structure (see Fig. 9a) also leads to a significant increase of LOI and decrease of PHRR. However DPHPOSS particles does not bear any reactive functions towards TB20D epoxy system and their lack of compatibility with T20BD can represent a limiting factor to disperse them properly at a nanoscale. These results indicate a similar trend as observed by Franchini et al. $^{4}$ on another epoxy system (DGEBA/MDEA) filled with non-soluble phenyl based POSS and phenyl or isobutyl epoxidized POSS.

Interestingly enough, the additional presence of $0.5 \mathrm{wt} \%$ of MWCNTs which allows to obtain a material exhibiting an electrical conductivity of $3.5 \times 10^{-3} \mathrm{~S} \mathrm{~m}^{-1}$ with respect to the value of $8.00 \times 10^{-13} \mathrm{~S} \mathrm{~m}^{-1}$ of the unfilled formulation, ${ }^{26-30}$ is found to not improve nor deteriorate the fire properties of POSS modified epoxy systems.

Mass loss calorimeter results indicate that during combustion both the total heat and the peak of the heat released by POSS modified T20B system do not vary significantly with addiction of MWCNTs while LOI value is found to be slightly lower than those obtained from the corresponding system without MWCNTs (T20BD + 5\% GPOSS). The thermal conductivity of MWCNTs is suspected to be responsible for such behavior. To support this observation, the residues were further analyzed visually and compared.

Fig. 11 shows the photographs of residues from left to right (neat T20BD, T20BD + 5\% DPHPOSS, T20BD + 5\% ECPOSS, T20BD $+5 \%$ GPOSS, T20BD $+5 \%$ TCPOSS).

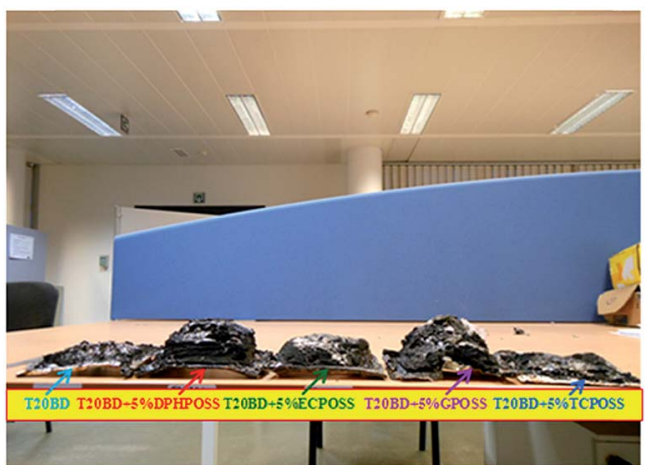

Fig. 11 Photographs of residues from left to right (neat T20BD, T20BD $+5 \%$ DPHPOSS, T2OBD + 5\% ECPOSS, T2OBD + 5\% GPOSS, T2OBD + $5 \%$ TCPOSS).

From the pictures, it can be seen that the neat T20BD system exhibits a continual crispy char relevant of quite a good thermostability of the neat system. Nevertheless, no intumescence is observed for this system without POSS. For the systems containing POSS particles, with the exception of TCPOSS based system, intumescent chars are obtained highlighting that the incorporation of POSS significantly enhances the thermostability of the char. GPOSS and DPHPOSS lead to the biggest intumescent chars.

The inclusion of MWCNTs is found to decrease and even suppress the intumescence effect brought by POSS particles, confirming thermal conduction takes place all over the material limiting the flame retardancy of the material. However, the residue of this system is found to exhibit a more compact aspect stressing the ability of MWCNTs to also promote char formation. In summary, MWCNTs appear to act following two antagonist ways.

Samples containing POSS have the THR almost constant in the limit of the experimental error. For these samples, the char yield from calorimetric data was also calculated, and the results were consistent with data obtained from the TGA in nitrogen atmosphere in the temperature range just after the main degradation step.

\subsection{Evaluation of the BAMPO and BAPPO as hardeners for improving fire properties}

3.2.1 Sample preparation. Dissolution tests of BAMPO and BAPPO in the epoxy mixture were performed with the aim of choosing the best conditions for the preparation of the samples.

Solubility test - BAMPO in TGMDA $+B D E$ at $70^{\circ} \mathrm{C}$. BAMPO and BAPPO were used in stoichiometric amount with respect to epoxy rings (epoxy rings of epoxy precursors + epoxy rings of reactive diluent).

In order to facilitate the dissolution in the epoxy mixture, the two synthesized organophosphorus compounds have been previously finely pulverized by mechanical stirring for several hours with a stirring speed of about $450 \mathrm{rpm}$. The pulverized compounds were held under vacuum for 3 hours in order to remove moisture before being embedded in the epoxy mixture. Fig. 12 shows finely pulverized BAMPO. 
The dissolution of BAMPO inside the epoxy blend was carried out through mechanical agitation using a magnetic stirrer $(400 \mathrm{rpm})$ in an heated oil bath $\left(70^{\circ} \mathrm{C}\right)$ for about 2 hours. After 2 hours, the mixture appeared to be fluid, caramel-colored and BAMPO particles were not visible to the naked eye. In Fig. 13 we can see the mixture poured into molds used for the fire testing that have been pre-heated to preserve its fluidity. Before the beginning of the curing process, the mixture was degassed at $45{ }^{\circ} \mathrm{C}$ for about 15 minutes. In Fig. 14 we can see the tested BAMPO based epoxy samples, before the curing process (see image on the left) and after extraction from the molds (see image on the right).

It is worth noting that different temperatures $(120,100,90$, $80{ }^{\circ} \mathrm{C}$ ) and different times of dissolution were tested. In all these cases the epoxy mixture became very viscous and partially crosslinked, thus preventing the solubilization of BAMPO. In Fig. 15 we can see the cross-linked BAMPO based epoxy sample after mechanical agitation in oil bath at $120^{\circ} \mathrm{C}$ for 5 minutes.

Solubility test - BAPPO in TGMDA + BDE at $80^{\circ} \mathrm{C}$. The dissolution of BAPPO in the epoxy blend was carried out through mechanical agitation using a magnetic stirrer $(400 \mathrm{rpm})$ in an heated oil bath $\left(80^{\circ} \mathrm{C}\right)$ for about 3 hours. After 2 hours, the mixture showed a creamy consistency and had a light brown color. Several particle aggregates and lumps of BAPPO molecules were detectable. However, it was possible to avoid the

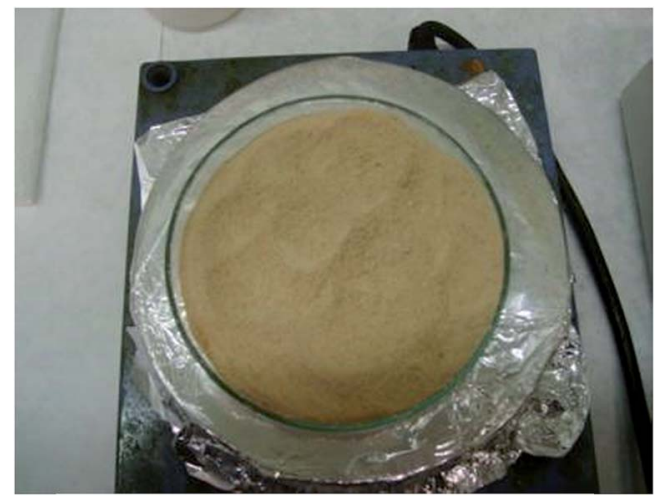

Fig. 12 Finely pulverized BAMPO.

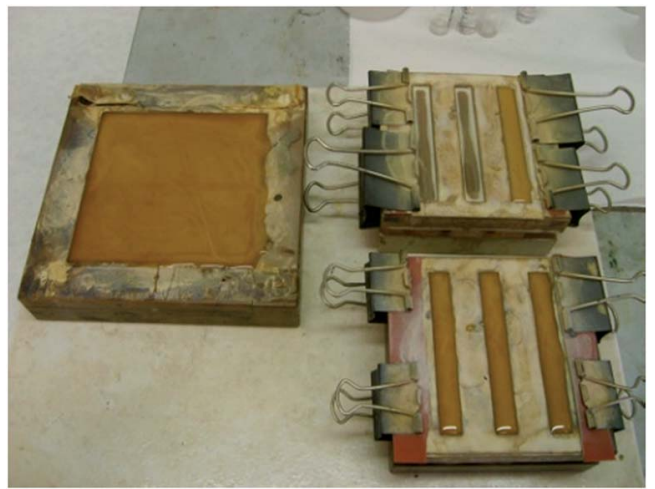

Fig. 13 BAMPO based uncured epoxy mixture poured into molds used for fire testing.

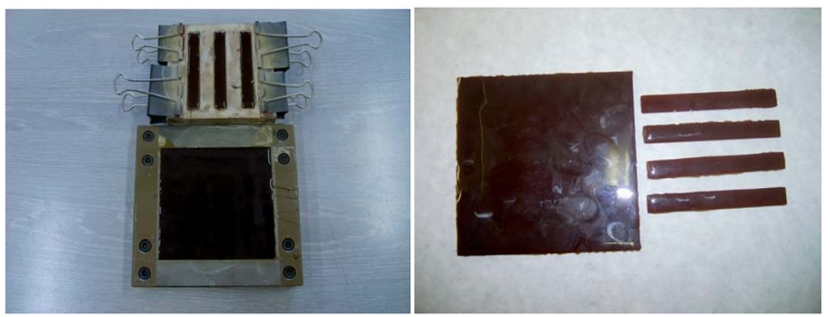

Fig. 14 Tested BAMPO based epoxy samples, before the curing process (see image on the left) and after the curing and extraction from the molds (see image on the right).

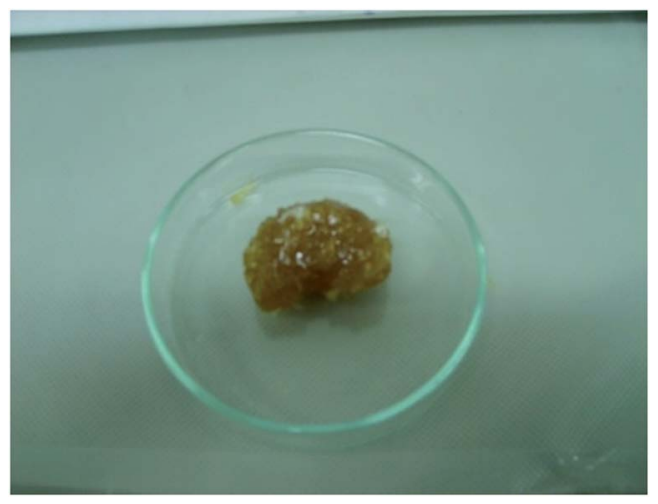

Fig. 15 Cross-linked BAMPO based epoxy sample at $120^{\circ} \mathrm{C}$.

formation of aggregates by slowly adding pulverized BAPPO particles in the epoxy mixture which was mechanically stirred $(400 \mathrm{rpm})$ in an heated oil bath at a higher temperature $\left(95^{\circ} \mathrm{C}\right)$ for about 3 hours. In this way, we obtained a homogeneous dispersion of the BAPPO particles in the epoxy mixture. It is worth noting that the solubility test performed at $120^{\circ} \mathrm{C}$ in an oil bath resulted in the crystallization and partial crosslinking of the BAPPO in the mixture after 1 hour. Before the beginning of the curing process, the mixture was degassed at $55{ }^{\circ} \mathrm{C}$ for about 15 minutes. In Fig. 16 we can see the tested epoxy samples containing BAPPO particle aggregates and lumps (solubilized in an oil bath at $80{ }^{\circ} \mathrm{C}$ for $3 \mathrm{~h}$ ) after extraction from the molds subsequently to the curing process.

Fig. 17 shows the tested epoxy sample containing BAPPO particles (solubilized in an oil bath at $95{ }^{\circ} \mathrm{C}$ for $3 \mathrm{~h}$ ) homogeneously dispersed after extraction from the molds subsequently to the curing process.

Fig. 18 shows the photo of the multifunctional tested sample T20BD + 5\% GPOSS + 0.5\% CNT (3100).

3.2.2 Thermogravimetric analysis. Thermal degradation both in air and in nitrogen of the samples BAMPO and BAPPO, shown in Fig. 19a, evidences that BAPPO is more stable toward thermal oxidative destruction than BAMPO.

The oxidative stability enhancement is of about $240^{\circ} \mathrm{C}$; in fact, for sample BAPPO sample, the beginning of the degradation occurs at about $340^{\circ} \mathrm{C}$ with respect to the temperature of $100{ }^{\circ} \mathrm{C}$ corresponding to BAMPO. The presence of phenyl group attached to the double bond $\mathrm{P}=\mathrm{O}$ most likely determines an increase of 


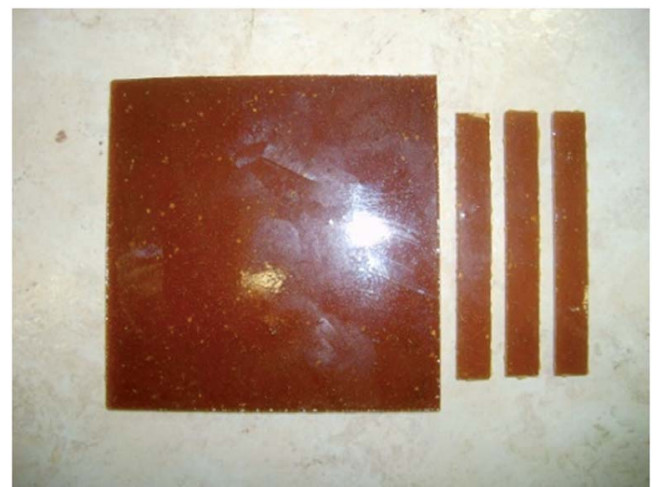

Fig. 16 Tested epoxy samples containing BAPPO particle aggregates and lumps.

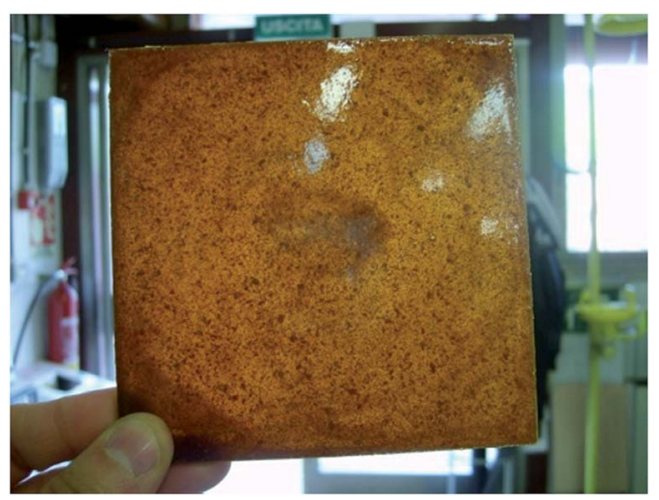

Fig. 17 Tested epoxy sample containing BAPPO particles homogeneously dispersed.

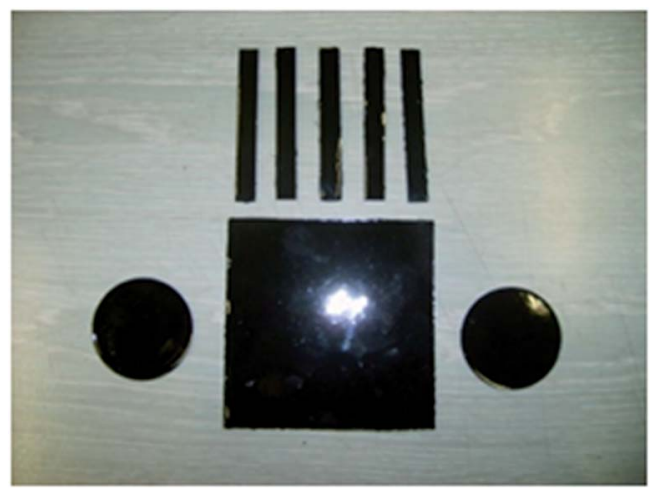

Fig. 18 Photo of the multifunctional tested sample T20BD $+5 \%$ GPOSS + 0.5\% CNT (3100).

the thermal stability of BAPPO with respect to that observed for BAMPO. First derivative TGA curves (in air and nitrogen) of BAMPO and BAPPO, shown in Fig. 19b, highlight some stages of degradation that in the TGA curves are not readily seen. In this regard, in air, a four-step and a three-step thermal degradation processes can be observed for BAMPO and BAPPO respectively, in nitrogen instead a three-step for BAMPO and a single-step for BAPPO thermal degradation processes can be observed.
TGA in air of BAMPO sample shows that at the end of the third stage at about $400{ }^{\circ} \mathrm{C}$ a weight loss of $55 \%$ was recorded. For both compounds BAMPO and BAPPO, the first stages of degradation are most probably due to degradation processes which do not involve oxygen (dehydration, random scission etc.), whereas the last steps are strongly dependent on the oxygen availability. This hypothesis is supported by the different trend of the thermogravimetric curves in inert $\left(\mathrm{N}_{2}\right)$ atmosphere (see graphics on the right in Fig. 19a and b).

TG profiles of BAMPO and BAPPO based composites in air and nitrogen are shown in Fig. 20.

The initial decomposition temperature is $360^{\circ} \mathrm{C}$ for BAMPO and BAPPO based composites (in air). This value is higher than the value detected for the pure epoxy formulation for which the initial decomposition occurs at $340^{\circ} \mathrm{C}$.

In nitrogen the resin filled with BAMPO shows the same initial decomposition of the pure epoxy formulation.

A very interesting aspect is the behavior of the BAPPO in the epoxy mixture; in fact, although the hardener agent alone starts to degrade at lower temperature with respect to the BAMPO hardener, no relevant differences between these two hardeners are detected in the stage of beginning degradation of the resins hardened with these curing agents.

3.2.3 Fire behavior of the epoxy mixture solidified with BAMPO and BAPPO. Table 3 shows the limiting oxygen index (LOI) and the values of the peak of heat release rate (PHRR).

Data shown in Table 3 clearly demonstrate that BAMPO and BAPPO hardeners are more efficient than DDS to increase the LOI of the epoxy system. The replacement of DDS with one of these two hardener act even better than the best performing POSS (GPOSS). Data in the first three lines of Table 3 also highlight that the PHRR of the epoxy systems decreases very significantly when BAMPO or BAPPO are used in comparison to DDS. Moreover, Fig. 21 shows that BAMPO and BAPPO lead to important intumescence of the systems when compared to the DDS based system. The presence of phosphorous moieties appears to act as a very efficient catalyst to char formation leading to a the creation of a protective layer that reduces the transfer of combustible gases.

When $0.5 \mathrm{wt} \%$ of MWCNTs are added to the epoxy systems with or without phosphorous in order to obtain a material exhibiting electrical conductivity, it appears that similarly to the epoxy systems containing a combination of MWCNTs and POSS nanoparticles, fire properties are not further improved due to antagonist actions of MWCNTs.

Concerning the values of THR, the use of BAMPO does not causes a variation in the total heat release which is instead affected by the presence of BAPPO.

BAMPO and BAPPO are both phosphineoxides, but in contrast to BAMPO, BAPPO is not fully soluble in the resin (see Section 3.2.1); moreover its presence considerably increases the viscosity. The difference in these mass loss calorimeter results is probably caused by the heterogeneity of the material leading to different degradation paths; the authors are performing other investigations to analyze in deep this phenomena. 

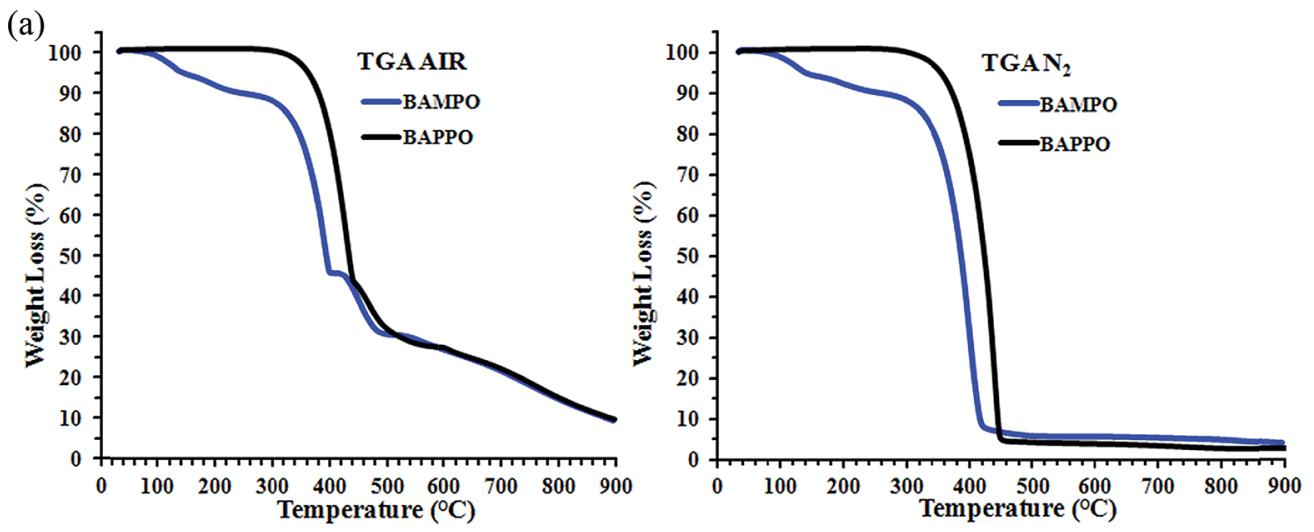

(b)
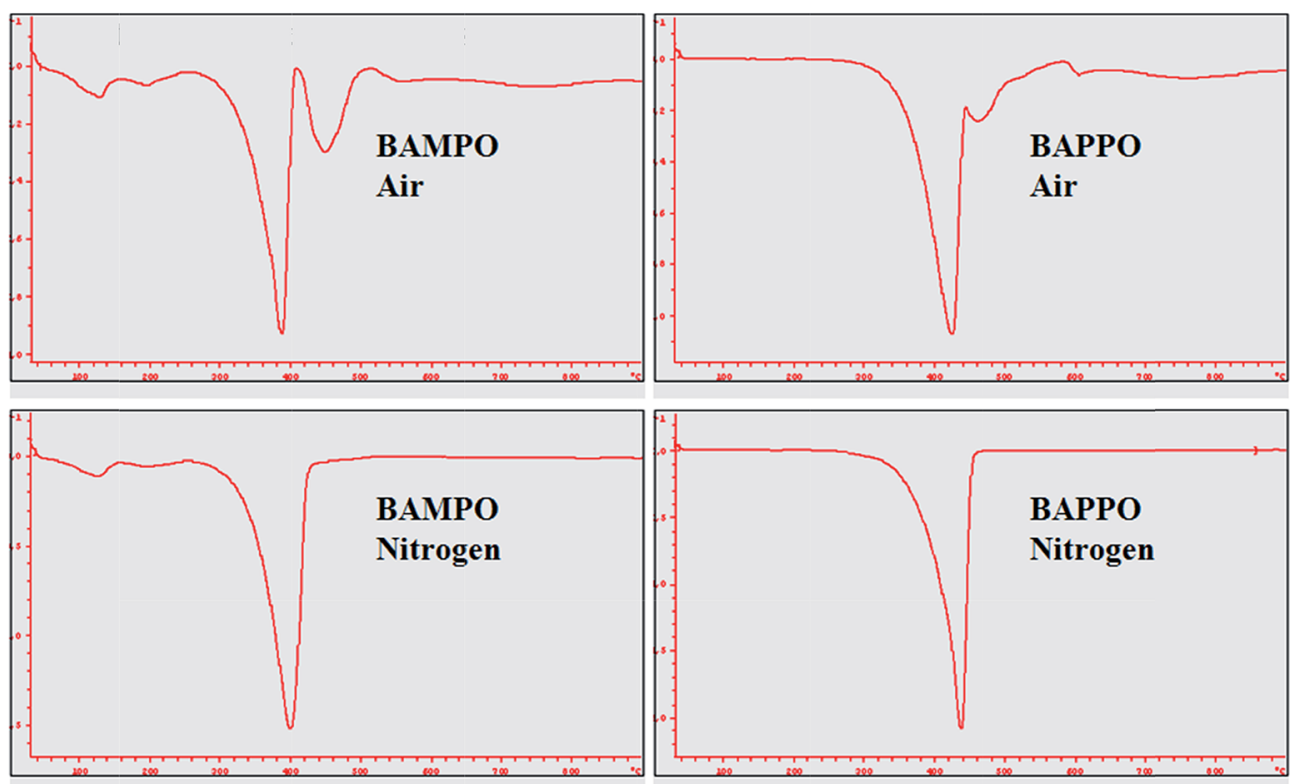

Fig. 19 (a) TG profiles of BAMPO and BAPPO in air atmosphere (on the left side), and in inert atmosphere (on the right side), (b) first derivative TGA curves (in air and nitrogen) of BAMPO and BAPPO.

The presence of CNT alone also affect, in a not negligible way, the THR, specifically for sample T20BD + 1\% CNT (3100) that shows the highest THR $\left(85 \mathrm{MJ} \mathrm{m}^{-2}\right)$. On the contrary, when CNTs are embedded in the resin containing POSS, BAMPO or
BAPPO the THR keeps the same value of the samples without CNT. In effect, as said before, depending on the chemical composition of the formulation, CNTs within epoxy systems cause 2 antagonist effects during combustion: (a) heat
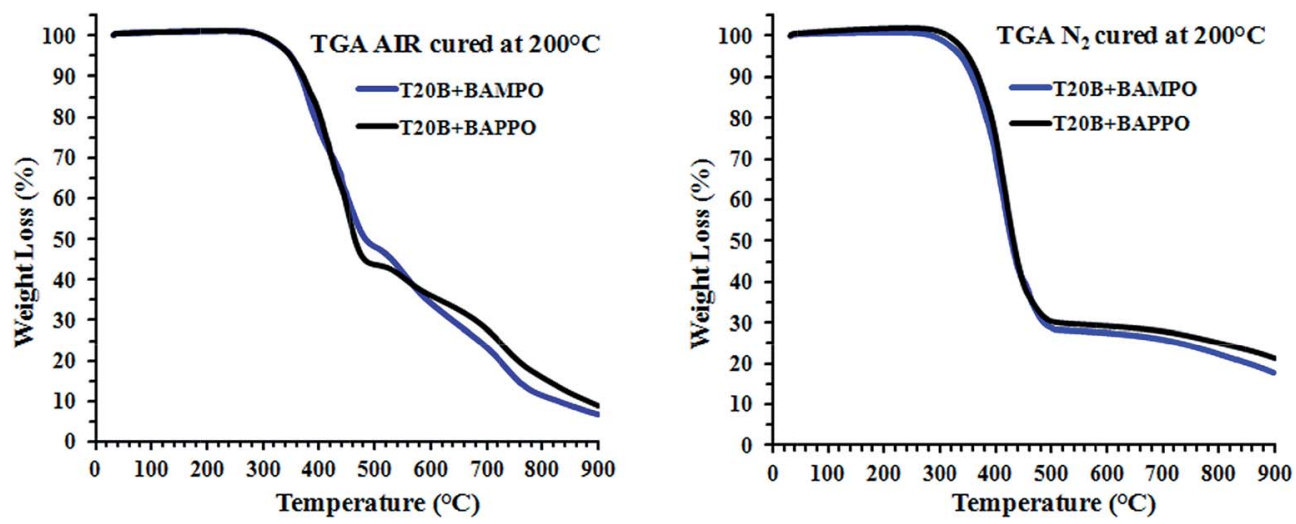

Fig. 20 TG profiles of BAMPO and BAPPO based composites in air and nitrogen. 
Table 3 LOI, PHRR and THR of the unfilled and filled T20B formulation cured with BAMPO and BAPPO

\begin{tabular}{llll}
\hline Sample & $\begin{array}{l}\text { LOI }\left(\% \mathrm{O}_{2}\right) \\
(\% \pm 1)\end{array}$ & $\begin{array}{l}\text { PHRR } \\
\left(\mathrm{kW} \mathrm{m}^{-2}\right)\end{array}$ & $\begin{array}{l}\text { THR } \\
\left(\mathrm{MJ} \mathrm{m}^{-2}\right)\end{array}$ \\
\hline T20BD & 27 & $540 \pm 81$ & $48 \pm 8$ \\
T20B + BAMPO & 40 & $447 \pm 80$ & $52 \pm 11$ \\
T20B + BAPPO & 36 & $379 \pm 72$ & $38 \pm 6$ \\
T20BD + 0.5\% CNT (3100) & 28 & $603 \pm 85$ & $68 \pm 10$ \\
T20BD + 1\% CNT (3100) & 28 & $629 \pm 110$ & $85 \pm 15$ \\
T20B + BAMPO + 0.5\% & 38 & $561 \pm 70$ & $53 \pm 8$ \\
CNT (3100) & & & \\
T20B + BAPPO (ns) + 0.5\% & 30 & $753 \pm 140$ & $31 \pm 9$ \\
CNT (3100) & & &
\end{tabular}

conduction all over the epoxy system leading to the decrease or even disappearance of intumescence and promotion of the degradation; (b) char promotion leading to the generation of more stable carbonaceous moieties and a more compact and important char obtained because of the capability of CNTs to trap radicals responsible for volatile formation.

For sample containing only CNTs, the first effect dominates and a slightly deterioration of the fire properties is observable; for the other samples containing CNT (samples hardened with BAMPO, or BAPPO containing POSS), the combination of these two effects is reflected in the obtained results. The same trend is also observed for the results from oxygen index tests.

Therefore when $0.5 \mathrm{wt} \%$ of MWCNTs are added to the epoxy systems with phosphorous or POSS compounds, in order to obtain a material exhibiting higher electrical conductivity with respect to the conductivity of the epoxy matrix alone, it appears that fire properties are unchanged, due to these antagonist actions of MWCNTs.

More precisely, MWCNTs embedded inside the epoxy matrix to increase electrical conductivity do not lead to the formation of intumescent charring (see Fig. 22); in fact, the presence of the nanotubes seems to favor some densification of the char. In addition, the presence of MWCNTs does not improve the PHRR values of the epoxy system, because most likely CNTs could act as heat conductors. However, CNTs exhibit an interesting potential to improve LOI and decrease PHRR value of the epoxy

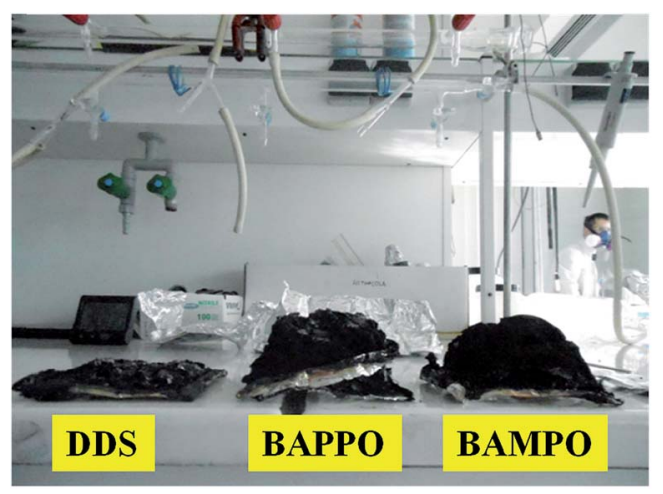

Fig. 21 Char aspect of T20B systems with different hardeners.

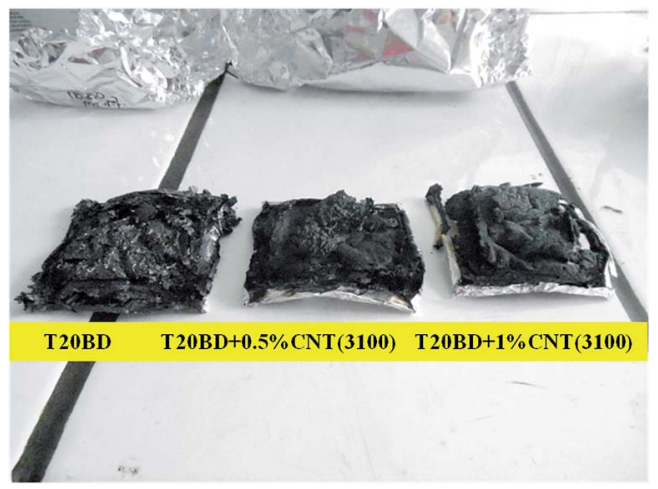

Fig. 22 Char aspect of T20BD + CNTs composites.

resin solidified with BAMPO with respect to the nanofilled sample solidified with DDS (T20B $+0.5 \%$ CNT (3100)). The last four samples in Table 3 refer to resins with conductive MWCNTs embedded inside the epoxy mixture. The best performance in terms of flame retardant of the multifunctional composites is obtained for the nanofilled sample solidified with BAMPO. For this last formulation (T20B + BAMPO + 0.5\% CNT (3100)) we detected a value in dc conductivity of $1.68 \times 10^{-1} \mathrm{~S} \mathrm{~m}^{-1}$. A very similar value in the electrical conductivity was obtained for the same formulation solidified with BAPPO.

It is worth noting that for the chosen concentration of MWCNTs ( $0.5 \mathrm{wt} \%)$, the electrical conductivity of the nanofilled sample is beyond the electrical percolation threshold (EPT) ${ }^{26}$

Thermogravimetric characterization of nanofilled samples. Fig. 23 and 24 show the thermogravimetric curves in air and nitrogen of the multifunctional epoxy formulations nanofilled with MWCNTs.

Similar to the thermogravimetric curves of POSS and BAMPO/BAPPO epoxy mixtures, two-step thermal degradation process can be observed for all the samples in air and nitrogen. The main initial stage of thermal degradation of the nanofilled samples substantially occurs in the temperature range of

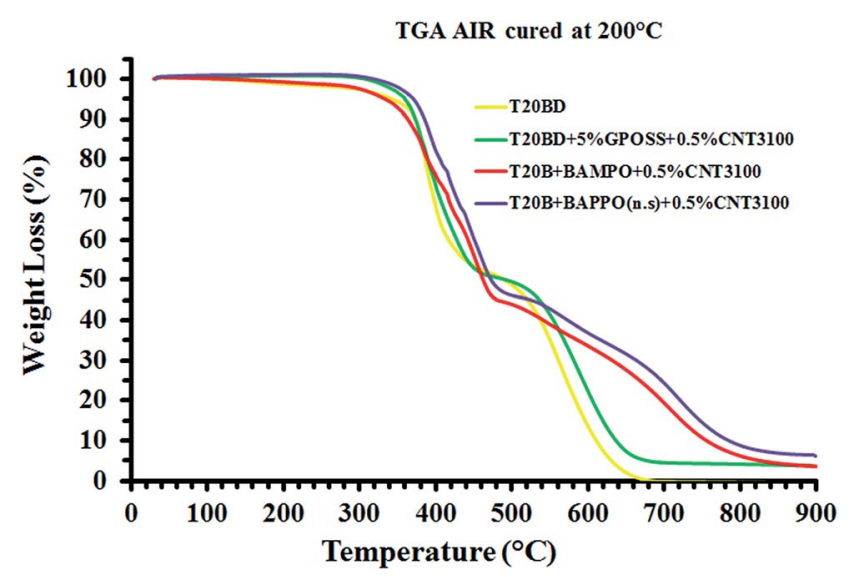

Fig. 23 Thermogravimetric curves in air of the pure epoxy formulation T20BD and the multifunctional epoxy formulations nanofilled with CNTs. 


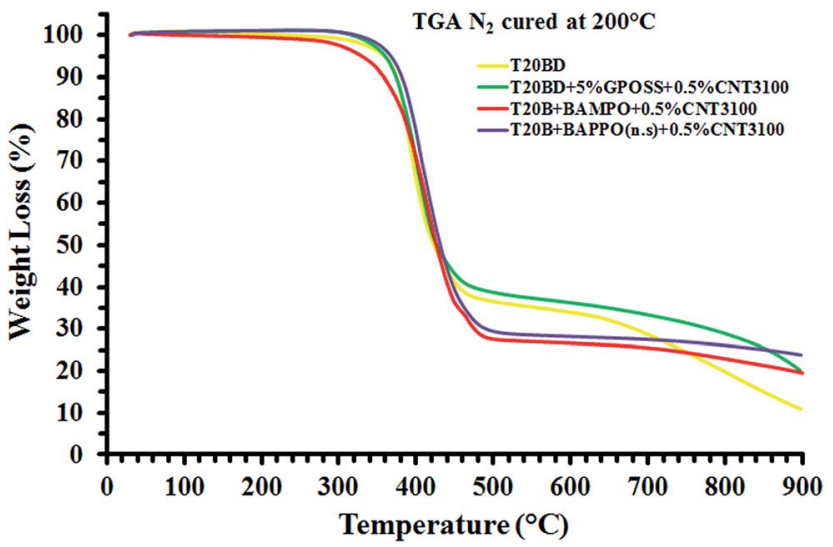

Fig. 24 Thermogravimetric curves in nitrogen of the pure epoxy formulation T20BD and the multifunctional epoxy formulations nanofilled with CNTs.

380-480 ${ }^{\circ} \mathrm{C}$. In fact, in this first stage only the unfilled sample (T20BD) and the sample hardened with BAMPO show a very slight weight loss $(\sim 5-6 \%)$ in the temperature range between $200{ }^{\circ} \mathrm{C}$ and $350{ }^{\circ} \mathrm{C}$. In air, the end of the first stage at about $460{ }^{\circ} \mathrm{C}$ involves almost the same mass loss for all the nanofiller; only very small decreases in the weight loss of the unfilled sample and the sample with GPOSS are detected. In the second stage of the thermal degradation, the hardeners BAMPO and BAPPO determine a decisive increase in the stability, and the weight loss (\%) go to $5,6 \%$ at $900{ }^{\circ} \mathrm{C}$, the higher investigated temperature. In the inert atmosphere, the second stage is much slower. The best behavior is detected for the unfilled sample and the sample containing GPOSS. The beginning of the first stage, being equal both in air and in nitrogen, is most probably due to degradation processes which do not involve oxygen (dehydration, random scission etc.), whereas the second step is strongly dependent on the oxygen availability. This hypothesis is supported by the different trend of the thermogravimetric curves in inert $\left(\mathrm{N}_{2}\right)$ atmosphere and in air.

\section{Conclusions}

The incorporation of $5 \%$ of POSS into T20BD epoxy resins is beneficial for improving its flame retardancy. The most promising POSS compounds are GPOSS and DPHPOSS. Data on the dispersion of the analyzed POSS within the epoxy mixture T20B show that the structure of the POSS compound plays an important role on the dissolution/dispersion of these compound into the matrix. GPOSS was solubilized in the matrix using two steps: ultrasonication at $90{ }^{\circ} \mathrm{C}$ and magnetic stirring in oil bath at $120^{\circ} \mathrm{C}$ for $1 \mathrm{~h}$.

The chosen procedure allows a good level of dissolution into the initial liquid epoxy mixture. This result is most probably due to the structure of GPOSS that is fully epoxidized with glycidyl groups which makes compatible the POSS molecule with epoxy precursors and reactive diluent. In addition, its structure allows the reaction and inclusion into the T20BD network formation during the curing cycle. This could explain the better fire behavior of GPOSS compared to the other analyzed POSS.

Another relevant result of this work regards the fire behavior of DPHPOSS which leads to epoxy system fire enhancement thanks to its aromatic pendant groups although it does not solubilize in the initial epoxy precursors. In fact, homogeneous dispersions of very small aggregates of DPHPOSS are achieved thanks to ultrasonication.

BAMPO and BAPPO have been synthesized and used as curing agent for the epoxy system based on the TGMDA. The obtained formulations have been characterized and the fire properties have been studied. The results show that the synthesized phosphorus based hardeners are more efficient than DDS to increase epoxy system LOI. The PHRR of the epoxy system decreases when BAMPO or BAPPO are used in comparison to DDS. Moreover, BAMPO and BAPPO lead to important intumescence of the systems when compared to DDS based system.

Multifunctional epoxy resins characterized by improved flame resistance were modified by incorporating electro-conductive nanofillers (CNTs). DC conductivity $\left(\mathrm{S} \mathrm{m}^{-1}\right)$ values of the multifunctional resins are found to range between $3.5 \times 10^{-3}$ and $1.68 \times 10^{-1}$. LOI $\left(\% \mathrm{O}_{2}\right)$ values range between 30 and 38 and PHRR values $\left(\mathrm{kW} \mathrm{m}^{-2}\right)$ range between 293 and 753. The best compromise of performance of the multifunctional composites is obtained for the nanofilled sample solidified with BAMPO. More precisely, the formulation (T20B + BAMPO + 0.5\% CNT (3100)) exhibits a DC conductivity of $1.68 \times 10^{-1} \mathrm{~S} \mathrm{~m}^{-1}$. The lower value of PHRR (293 kW m $\mathrm{m}^{-2}$ ) is obtained for the multifunctional nanocomposite T20BD + 5\% GPOSS + 0.5\% CNT (3100). For this last formulation the DC conductivity is $3.5 \times 10^{-3} \mathrm{~S} \mathrm{~m}^{-1}$ whereas it is $8.00 \times 10^{-13} \mathrm{~S} \mathrm{~m}^{-1}$ for the unfilled formulation confirming the successful obtainment of a multifunctional formulation.

\section{Acknowledgements}

The research leading to these results has received funding from the European Union's Seventh Framework Programme for research, technological development and demonstration under Grant Agreement no. 313978.

\section{References}

1 C. Gérard, G. Fontaine, S. Bellayer and S. Bourbigot, Reaction to fire of an intumescent epoxy resin: Protection mechanisms and synergy, Polym. Degrad. Stab., 2012, 97, 1366-1386.

2 X. Wang, L. Song, H. Yang, W. Xing, B. Kandola and Y. Hu, Simultaneous reduction and surface functionalization of graphene oxide with POSS for reducing fire hazards in epoxy composites, J. Mater. Chem., 2012, 22, 22037-22043.

$3 \mathrm{~J}$. D. Lichtenhan and J. W. Gilman, Preceramic additives as fire retardants for plastics, US 6,362,279 B2, issued March 26, 2002.

4 E. Franchini, J. Galy, J. F. Gérard, D. Tabuani and A. Medici, Influence of POSS structure on the fire retardant properties 
of epoxy hybrid networks, Polym. Degrad. Stab., 2009, 94, 1728-1736.

5 J. Green, Mechanisms for Flame Retardancy and Smoke suppression -A Review, J. Fire Sci., 1996, 14, 426-442.

6 B. Schartel, Phosphorus-based Flame Retardancy Mechanisms-Old Hat or a Starting Point for Future Development?, Materials, 2010, 3, 4710-4745.

7 F. Laoutid, L. Bonnaud, M. Alexandre, J. M. López-Cuesta and P. Dubois, New prospects inflame retardant polymermaterials: From fundamentals to nanocomposites, Mater. Sci. Eng., R, 2009, 63, 100-125.

8 S. Y. Lu and I. Hamerton, Recent developments in the chemistry of halogen-freeflame retardant polymers, Prog. Polym. Sci., 2002, 27, 1661-1712.

9 M. Lewin and E. D. Weil, Mechanisms and modes of action in flame retardancy of polymers, in Fire Retardant Materials, ed. A. R. Horrocks and D. Price, Woodhead Publishing, Cambridge UK, 2001, pp. 31-68.

$10 \mathrm{~S}$. V. Levchik and E. D. Weil, Thermal decomposition, combustion and flame-retardancy of epoxy resins-a review of the recent literature, Polym. Int., 2004, 53, 19011929.

11 W. K. Chin, M. D. Shau and W. C. Tsai, Synthesis, structure, and thermal properties of epoxy-imide resin cured by phosphorylated diamine, J. Polym. Sci., Part A: Polym. Chem., 1995, 33, 373-379.

12 S. V. Levchik, G. Camino, M. P. Luda, L. Costa, G. Muller, B. Costes and Y. Henry, Epoxy resins cured with aminophenylmethylphosphine oxide 1: Combustion performance, Polym. Adv. Technol., 1996, 7, 823-830.

13 Y. L. Liu, G. H. Hsiue, R. H. Lee and Y. S. Chiu, Phosphoruscontaining epoxy for flame retardant. 3. Using phosphorylated diamines as curing agents, J. Appl. Polym. Sci., 1997, 63, 895-901.

14 G. H. Hsiue, Y. L. Liu and J. Tsiao, Phosphorus-containing epoxy resins for flame retardancy V: Synergistic effect of phosphorus-silicon on flame retardancy, J. Appl. Polym. Sci., 2000, 78, 1-7.

15 Y. L. Liu, G. H. Hsiue, C. W. Lan and Y. S. Chiu, Phosphoruscontaining epoxy for flame retardance. 4. Kinetics and mechanism of thermal degradation, Polym. Degrad. Stab., 1997, 56, 291-299.

16 C. S. Wang and J. Y. Shieh, Synthesis and properties of epoxy resins containing bis(3-hydroxyphenyl) phenyl phosphate, Eur. Polym. J., 2000, 36, 443-452.

17 I. K. Varma and U. Gupta, Curing of Epoxy Resin with Phosphorylated Diamine, J. Macromol. Sci., Part A, 1986, 23(1), 19-36.

18 M. D. Shau and T. S. Wang, Syntheses, Structure, Reactivity, and Thermal Properties of New Cyclic Phosphine Oxide Epoxy Resins Cured by Diamines, J. Polym. Sci., Part A: Polym. Chem., 1996, 34, 387-396.

19 K. Tao, S. Yang, J. C. Grunlan, Y. S. Kim, B. Dang, Y. Deng, R. L. Thomas, B. L. Wilson and X. Wei, Effects of carbon nanotube fillers on the curing processes of epoxy resinbased composites, J. Appl. Polym. Sci., 2006, 102, 5248-5254. 20 P. Jyotishkumar, E. Logakis, S. M. George, J. Pionteck, L. Häussler, R. Haßler, P. Pissis and S. Thomas, Preparation and properties of multiwalled carbon nanotubes/epoxy-amine composites, J. Appl. Polym. Sci., 2013, 127, 3063-3073.

21 C. Katsoulis, E. Kandare and B. K. Kandola, The combined effect of epoxy nanocomposites and phosphorus flame retardant additives on thermal and fire reaction properties of fiber reinforced composites, J. Fire Sci., 2011, 29, 361-383.

22 S. K. Lee, B. C. Bai, J. S. Im and Y. S. Lee, Flame retardant epoxy complex produced by addition of montmorillonite and carbon nanotube, J. Ind. Eng. Chem., 2010, 16, 891-895.

23 S. S. Rahatekar, M. Zammarano, S. Matko, K. K. Koziol, A. H. Windle, M. Nyden, T. Kashiwagi and J. W. Gilman, Effect of carbon nanotubes and montmorillonite on the flammability of epoxy composites, Polym. Degrad. Stab., 2010, 95, 870-879.

24 U. Braun, A. I. Balabanovich, B. Schartel, U. Knoll, J. Artner, M. Ciesielski, M. Döring, R. Perez, J. K. W. Sandler, V. Altstädt, T. Hoffmann and D. Pospiech, Influence of the oxidation state of phosphorus on the decomposition and fire behaviour of flame-retarded epoxy resin composites, Polymer, 2006, 47, 8495-8508.

25 T. Kashiwagi, Progress in Flammability Studies of Nanocomposites with New Types of Nanoparticles, in Flame Retardant Polymer Nanocomposites, ed. A. B. Morgan and C. A. Wilkie, John Wiley \& Sons, Inc., Hoboken, New Jersey, 2007, ch.10, pp.285-324.

26 L. Guadagno, M. Raimondo, V. Vittoria, L. Vertuccio, C. Naddeo, S. Russo, B. De Vivo, P. Lamberti, G. Spinelli and V. Tucci, Development of epoxy mixtures for application in aeronautics and aerospace, RSC Adv., 2014, 4, 15474-15488.

27 L. Guadagno, M. Raimondo, V. Vittoria, L. Vertuccio, K. Lafdi, B. De Vivo, P. Lamberti, G. Spinelli and V. Tucci, The role of carbon nanofiber defects on the electrical and mechanical properties of CNF-based resins, Nanotechnology, 2013, 24, 305704.

28 B. D. Vivo, L. Guadagno, P. Lamberti, M. Raimondo, G. Spinelli, V. Tucci, L. Vertuccio and V. Vittoria, Electrical properties of multi-walled carbon nanotube/tetrafunctional epoxy-amine composites, AIP Conf. Proc., 2012, 1459, 199201.

29 L. Guadagno, B. De Vivo, A. Di Bartolomeo, P. Lamberti, A. Sorrentino, V. Tucci, L. Vertuccio and V. Vittoria, Effect of functionalization on the thermo-mechanical and electrical behavior of multi-wall carbon nanotube/epoxy composites, Carbon, 2011, 49, 1919-1930.

30 B. De Vivo, P. Lamberti, G. Spinelli, V. Tucci, L. Guadagno, M. Raimondo, L. Vertuccio and V. Vittoria, Improvement of the electrical conductivity in multiphase epoxy-based MWCNT nanocomposites by means of an optimized clay content, Compos. Sci. Technol., 2013, 89, 69-76. 